\title{
Exploration of a smart glasses teleconference system for virtual instructional coaching
}

\author{
Kristina Zaccaria
}

Follow this and additional works at: https://researchrepository.wvu.edu/etd

\section{Recommended Citation}

Zaccaria, Kristina, "Exploration of a smart glasses teleconference system for virtual instructional coaching" (2018). Graduate Theses, Dissertations, and Problem Reports. 7285.

https://researchrepository.wvu.edu/etd/7285

This Dissertation is protected by copyright and/or related rights. It has been brought to you by the The Research Repository @ WVU with permission from the rights-holder(s). You are free to use this Dissertation in any way that is permitted by the copyright and related rights legislation that applies to your use. For other uses you must obtain permission from the rights-holder(s) directly, unless additional rights are indicated by a Creative Commons license in the record and/ or on the work itself. This Dissertation has been accepted for inclusion in WVU Graduate Theses, Dissertations, and Problem Reports collection by an authorized administrator of The Research Repository @ WVU.

For more information, please contact researchrepository@mail.wvu.edu. 
Exploration of a smart glasses teleconference system for virtual instructional coaching

\section{Kristina Zaccaria}

Dissertation submitted to the College of Education and Human Services at West Virginia University in partial fulfillment of the requirements for the degree of

\section{Doctor of Education}

in

Educational Psychology

Reagan Curtis, Ph.D., Committee Chairperson M Cecil Smith, Ph.D.

Sharon Hayes, Ph.D.

Cathy Scutta, OTD, BCBA-D

Department of Learning Sciences and Human Development

\section{Morgantown, West Virginia} 2018

Keywords: Instructional coaching, virtual coaching, smart glasses teleconference system, adoption 


\title{
Abstract \\ EXPLORATION OF A SMART GLASSES TELECONFERENCE SYSTEM FOR VIRTUAL INSTRUCTIONAL COACHING
}

\begin{abstract}
Kristina Zaccaria
Coaching is an effective practice that affects teacher and learner outcomes; however, instructional coaches (ICs) must be trained in the fidelity of the implementation. New technology provides an opportunity for new virtual coaching methods. The purpose of this exploratory case study is to explore coaches-in-training (CITs) perspectives of their exposure to the contingencies of virtual coaching with a smart glasses teleconference system compared to traditional on-site coaching within the general framework of coaching effectiveness. We conducted post-interviews after all training and coaching sessions, held an end-of-experience interview, conducted direct observations, and documented coaching activities that occurred with three participants during virtual and on-site coaching. CITs discussed experiences receiving coaching delivered through the smart glasses teleconference system.
\end{abstract}




\section{DEDICATION}

The author wishes to dedicate this dissertation in memory of my Dad and honor of my Mom for always believing in me. 


\section{ACKNOWLEDGMENTS}

This work would not have been possible without the support of "my village"-past and present. I am truly blessed to have so many people in my circle that have supported, loved, encouraged, and believed in me through this crazy journey! I love you all and am forever grateful-I truly could not have achieved this accomplishment without each of you.

A thank you from the bottom of my heart to my parents for being with me every step of this process. I do not have the words to express how grateful I am to each of you for everything you have done for me. Thank you for raising me with a belief that education is important and showing me the value of hard work. To my brother, Domenic-- thanks for encouraging and supporting me in your own way! Thank you to my many friends and extended family for your encouragement, understanding, patience, and support.

I would like to express my sincere appreciation to Dr. Reagan Curtis, my committee chair. Thank you for undertaking Dr. Hush's CLM Cohort under your wing. I sincerely appreciate all your feedback, and guidance throughout this process. Dr. Sharon Hayes, thank you for your time, valuable feedback, sharing of resources, and support. Special thanks to Dr. M Cecil Smith, for your willingness to join my committee at the last moment.

I would like to express my deepest gratitude to my mentor and committee member Dr. Cathy Scutta. I would have never made it through the Doctoral program without your unwavering support and your advice to "learn everything you can from anyone that will teach you, and then decide what you believe." I am forever thankful for the opportunity to participate in the coordinator cohort which stretched me beyond what I thought was capable of. Thank you for your life lessons and making me a better person. To my fellow CLM Coordinators, each of you holds a very special place in my heart.

A huge thank you to our Doctoral cohort for the support and partnership through this process!

My sincere appreciation to Ms. Vicci Tucci, developer of the Competent Learner Model. I am grateful to be a part of the CLM family. I am blessed beyond measures to be a part of your life's work and watch the effects it has on students' lives every day.

Thank you to the many mentors that have influenced me personally and professionally. A special appreciation Dr. David Herr, your legacy of leading with kindness and compassion is with me always.

A sincere thank you to the three coaches-in-training who voluntarily participated in this study. Thank you for learning along with me, and jumping into this experience with both feet forward. Each of you is an awesome coach whom I am very proud to work alongside. A genuine thanks to the principals and special education directors in each school division for allowing me to conduct this study. To all the classroom teams who were coached by the coaches-in-training, thank you for trusting us to provide a new type of coaching in your classrooms. I am humbled by the work each one of you does to make each of your students successful. 


\section{TABLE OF CONTENTS}

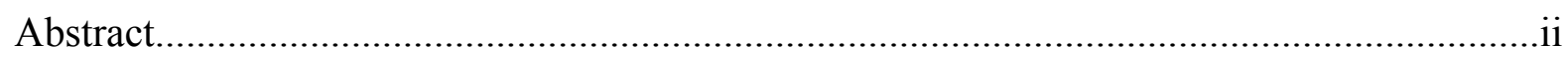

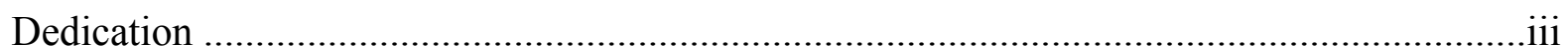

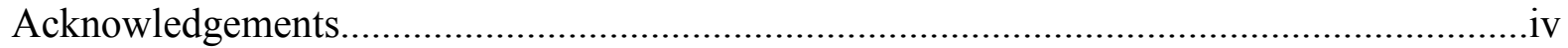

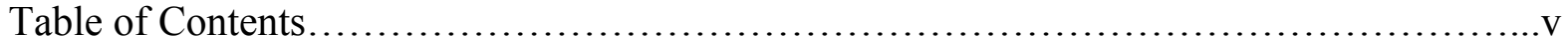

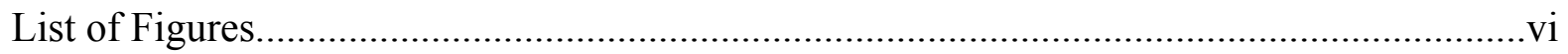

Introduction and Review of the Literature .................................................................. 1

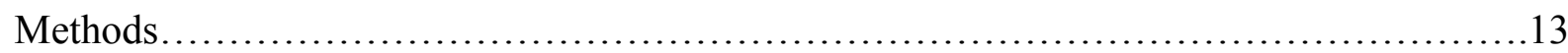

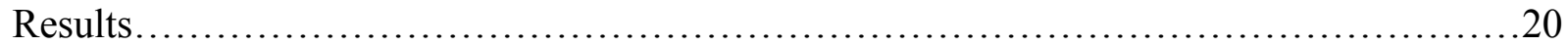

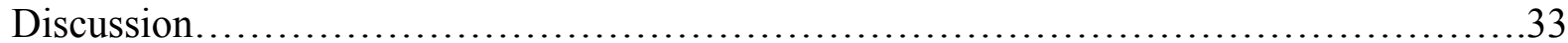

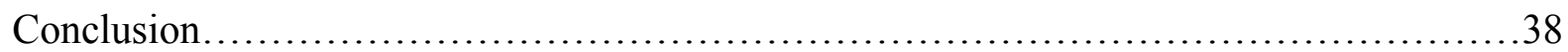




\section{LIST OF FIGURES}

Figure 1. Point-of-video video conferencing

Figure 2. The use of coaching best practices 


\section{Introduction and Review of the Literature}

Instructional coaches provide support to classroom instructors around evidence-based interventions, strategies, and models. The National Professional Development Center on Autism Spectrum Disorders Response to Intervention, Positive Behavioral Intervention Supports (Kucharczyk et al., 2012;2012; Knight 2009; Scott \& Martinek, 2006) and The Competent Learner Model are examples of models that employ coaching to support instructor skills and student growth. Within the Positive Behavioral Intervention Supports, ICs work directly with classroom instructors to determine the function of target behaviors, collaboratively identify evidence-based strategies to support students, outline specific steps and support for successful implementation of evidence-based practices, and provide on-going support to instructors to ensure high fidelity of implementation of interventions (Stormont \& Reinke, 2012).

The Competent Learner Model (CLM) is a team-based professional development program that includes tools and processes to establish consistency across all intervention efforts, contexts and team members (Scutta, 2017; Tucci, 2005; Tucci \& Hursh, 1988; Tucci \& Hursh, 1991; Tucci, Hursh, \& Laitinen, 2004; Tucci, Hursh, Laitinen, \& Lambe, 2005; Warash, Curtis, Hursh, \& Tucci, 2008). CLM coaching embeds behavioral-skills training, various types of modeling, written instructions, video examples, and face to face performance feedback for all team members as they learn how to implement the evidence-based interventions. These training methods have been found to have statistically significant positive associations with intervention implementation fidelity (Brock et al., 2017; Brock \& Carter, 2016; Chen, 2015; Hall, Grundon, Pope \& Romero, 2010).

All components of the program are theoretically grounded in and designed with empirically validated methods from Applied Behavior Analysis, Direct Instruction, Precision 
Teaching, Personalized System of Instruction, Instructional Coaching, and Implementation Science. CLM core components include: (For more information see: Competent Learner Model for Individuals with Autism/PDD, 2005).

1. Classroom staff training

a. Professional development modules- 17 online training modules to enhance instructors (i.e., instructors, paraprofessionals) instructional practices

b. Instructional coaching- trusted collaborator who provides coaching to instructors around the CLM tools

2. Student assessments and supplemental curriculum

a. Competent Learner Repertoire Assessment- curriculum-based assessment used to formulate Competent Learner Repertoires

b. Competent Learner Model Placement Test- indirect assessment used to place students in the supplemental curriculum

c. Supplemental curriculum- Instructors embed the repertoires within the supplemental curriculum across functional activities throughout the day so that students are provided frequent opportunities for students to apply the newly learned skill

3. Behavior Management

a. Instructors use the Designing Contingencies Manual to formulate individual behavior plans

4. Progress Monitoring and data collection

a. Collection of specific types of data collection matched to repertoires targeted to increase or decrease 
5. Classroom schedule

a. Instructional schedule for all learners

b. Activity schedule for all instructors

The Competent Learner Model has shown to improve student outcomes with improvements on the Vineland Adaptive Behavior Scales Assessment (Sparrow, Cicchetti, \& Sauliner, 2016) in the domains of interpersonal relations, play, and coping skills (Kubina \& Wolfe, 2007 \& Hineline \& Axelrod, 2007). Additionally, research has shown a positive relationship between satisfaction with CLM coaching and teacher efficacy in the ability to apply concepts within the supplemental curriculum to students in their classroom (Polly, 2013 \& Kissinger, 2014). Ketley (2017) found that after instructors (i.e., paraprofessionals, teachers) received coaching in the model, they had a basic understanding of the concepts within Applied Behavior Analysis. Similarly, Medicino (2015) evaluated the impact of a partnership-based model of collaborative consultation (as the theoretical framework for coaching) on the acquisition and implementation integrity of concepts within the Competent Learner Model. Findings demonstrated classroom teams had sustained levels of treatment integrity after receiving coaching grounded in a partnership-collaborative process.

Instructional coaching offers a way to ensure that all students have access to sufficient evidence-based practices that are implemented with fidelity and sustained over time (Aguilar, 2014). ICs utilize a repertoire of coaching competencies, including the willingness and ability to build relationships, provide positive and specific feedback, develop trust, facilitate learning, and hold themselves accountable for outcomes (Duda \& Barrett, 2014). ICs perform different coaching practices with instructors in classrooms including modeling, observing, engaging in reflective conversations, giving performance feedback through side-by-side coaching 
mechanisms, and relationship-building strategies. Observation involves direct observation of the instructor. Modeling entails an IC demonstrating how to use the practice (Kretlow \& Bartholomew, 2010; Neuman \& Cunningham, 2009; Winton et al., 2015). Practices may include academic or behavioral strategies that are designed to improve student performance.

ICs use performance-based feedback to instructors who can occur through delayed feedback mechanisms or in-vivo. Delayed feedback may occur during post-conferences. Feedback is most effective when it is specific, positive, timely, and corrective if warranted (Scheeler, Ruhl, \& McAfee, 2004; Solomon, Klein, \& Politylo, 2012). Feedback is considered timely when it is delivered within roughly the same day of an observation (Scheeler et al., 2004). Side-by-side coaching, provided by the IC to the instructor, allows instructors to receive in-vivo feedback specific to the accuracy of their implementation of new teaching behaviors (Kretlow, 2010).

ICs develop positive instructor-coach relationships, called alliances (Ippolito, 2010; Snyder, Hemmeter, \& Fox, 2015; Mraz, Algozzine, \& Watson, 2008; Neufeld \& Roper, 2003; Shanklin, 2006; Wehby, Maggin, Partin, \& Robertson, 2012). ICs build positive relationships with instructors to develop trust and communication. Other allegiance building strategies include the IC being collaborative with instructors, having expertise in the content area in which they are providing coaching, and communicating to the instructor that the ICs involvement is nonevaluative (Pierce, 2015).

Training for ICs. For coaching to be effective, ICs must be trained to achieve the fidelity of the implementation and must also develop effective intrapersonal skills. The quality of ICs is the greatest factor in the success of any coaching model (Brestlow, 2017). Many ICs have little or no training before taking a position as a coach (Aguilar, 2016). It is important for school 
divisions to provide ongoing training and support for their coaching workforce. ICs work with CITs to set and monitor goals for growth and are engaged in a professional learning process that mirrors the process they facilitate for instructors (Brestlow, 2017). Special attention should be devoted to performance feedback linked to the fidelity of the intervention and anticipated outcomes (Duda, 2014). Reflective consultation is a variation on a coaching relationship that may be used by a supervisor in supporting a CIT to use the effective coaching strategies discussed above while also allowing the CIT to reflect upon their experiences as ICs to gain insights for improvement or changing aspects of coaching practices (Kucharczyk, 2012). Reflective consultation sessions between an IC and CIT typically occur between a coaching sequence of pre-observation, observation, and post-observation so that both coaches can reflect upon what occurred during that sequence and reflect on any challenges.

Coaching contexts. Traditionally coaching occurs face-to-face at on-site locations (i.e., school, classroom, worksite). The high cost of instructional coaching models and the challenge of finding high-quality ICs often provide implementation challenges for sustainability and growth of this type of professional development program (Breslow, 2017). Additionally, as educational systems around the world evolve to meet the changing workforce demands and requests for educational reform, many of the supplemental duties required in the data-driven age of accountability have put a significant time constraints on instructors (Chamberlain, 2008; Darling \& Hammond, 2000; Fullan, 2009; Quintis, 2011; Rossides, 2004; Shidler, 2009; Terry, 2010; Varlas, 2010).

Virtual or e-coaching has emerged as a new delivery method for coaching in the last several years. E-coaching may employ telephones, email, or video conferencing (e.g., Skype). Video conferencing typically utilizes an online social platform (i.e., Skype, Zoom) where the 
coach and person being coached can meet face-to-face from remote locations. Video conferencing uses a two-way video and two-way audio.

The use of technology for coaching helps to reduce the costs of coaching while providing access to timely learning experiences (Ehsanipour, \& Zaccarelli, 2017; White, Howell, Kunz, \& Nugent, 2015) that can be delivered privately and conveniently. Virtual ICs who provide off-site coaching support can manage a larger caseload than can in-person ICs by eliminating the time spent traveling from school to school (Brestlow, 2017). Similarly, virtual ICs increases

efficiency by reducing scheduling and other logistical challenges such as time for the instructor and IC to meet for pre-and post-conferences (Brestlow, 2017).

Additionally, virtual coaching can provide a cost-efficient means to train ICs (Ahrend, Diamond, \& Webber, 2010). As educational systems shift to providing personalized instructional models for both students and instructors, there is an even greater need for ICs who can provide skillful support targeted to instructors' specific learning needs (Brestlow, 2017).

The IC is unable to give feedback immediately to the CIT through video conferencing. All feedback occurs through post-conferences after the IC has observed the CIT delivering the lesson or the IC provides written text through video conferencing and the CIT obtains this feedback after the delivery of the lesson. Another form of virtual coaching is bug-in-the ear coaching. Virtual bug-in-ear coaching uses advanced online and mobile technology that allows ICs to remotely observe classroom instruction and offer discreet feedback to the CIT through an earpiece (Rock, et al., 2009). Project TEEACH determined that bug-in-ear coaching is a practical, efficient, and costeffective way to provide immediate feedback to instructors (Rock, 2009).

Bug-in-ear coaching uses a camera located on a device at the coaching location (Rock et al., 2014). Bug-in-ear coaching uses wide-angle cameras to capture a larger picture of the 
environment. However, the IC is only able to see the area the camera expands. Coogle, Rahn, \& Ottley (2014) used typical cameras with video-conferencing robots (i.e., Swivl ${ }^{\mathrm{TM}}$ ) that rotate the computer equipment (i.e., laptop, $\mathrm{Pad}^{\mathrm{TM}}$ ) to capture the environment. Instructors and students moved throughout the classroom enhancing the feasibility by presenting a better view of the classroom for the IC to observe. However, both options provide limitations of the IC being able to observe the CIT and class making transitions throughout the building. Additionally, the equipment set-up needed for environments such as playgrounds or cafeterias is prohibitive. New advancements in the technology field, offer additional remote options for instructional coaching.

\section{Live-stream smart glasses teleconference system}

Smart glasses resemble eye glasses; however, smart glasses have built-in cameras, allowing remotely located ICs to observe in real-time, the CITs point-of-view. Thus, the IC can see what the CIT sees. Smart glasses teleconference systems employ two-way audio, and a oneway video. The CIT can communicate with the remote IC, however, cannot see them. Smart glasses are already redefining instruction, training, and coaching (Porter \& Happelmann, 2017) by providing a point-of-view observation that previously did not exist. According to a survey conducted by the Augmented Reality for Enterprise Alliance (2016), many industries could benefit from implementation and use of smart glasses systems. However, aerospace, automotive, life sciences, and manufacturing sectors have been the earliest adopters. The ability to accelerate completion of tasks via step-by-step instructions at the point of work is a key driver in smart glasses adoption (Augmented Reality for Enterprise Network, 2016).

Smart glasses have many of the same features as bug-in-ear technology. One advantage is that smart glasses require no additional equipment set up in the coaching location. The use of a live-stream smart glasses teleconferencing system as a coaching delivery mechanism is limited in 
public-school settings. Little is known about the uses of smart glasses and the perception of ICs and CITs for instructional coaching (Rauschnabel, Brem, \& Ivens, 2015).

\section{Theoretical Framework}

Implementation science is the study of factors that influence the full and effective use of innovations in practice (National Implementation Research Network, 2016). Implementation science utilizes a systematic framework to (a) organize current knowledge into useful frameworks, (b) develop strategies to support implementation and scale up evidence-based programs, (c) establish relevant measures of implementation factors in practice, and (d) improve the predictive validity of the theoretical frameworks and the precision of measures. Active implementation frameworks take advantage of transdisciplinary knowledge bases (e.g., research implementation, collaboration, dialogue methods for knowledge synthesis, and integration methods) and account for complexity inherent in human organizations and systems that are intractable and ever-changing (Fixsen, Naaom, Blasé, Friedman, \& Wallace, 2005). Active implementation frameworks include:

1) effective and usable innovations

2) implementation stages- exploration, installation, initial implementation, and full implementation

3) improvement cycles- plan, do, study, act (PDSA) cycles, practice-policy communication, and usability testing

4) implementation teams to promote organizational and system change (Fixsen, 2005). 
Active implementation frameworks provide a theoretical base for organizing the education field and a new beginning of an expansion of knowledge related to the implementation of best practices, science, and policy.

Usable innovations include (a) a clear description of the program, (b) a description of the essential functions that define the program, (c) definitions of the essential functions, and (d) practical assessment of the performance of practitioners who use the program (National Implementation Research Network, 2016). Innovations need to be teachable, learnable, doable and readily assessed into practice (Dakelab, Hedge, \& Sundstrom, 2017). Key attributes of a successful innovation include advantages over the existing method, compatibility within the culture of the organization, low complexity, easily observed benefits, clear potential for work improvement, and easily available support components (Greenhalagh, Macfarlane, Bate, \& Kyrikakidou (2004).

Purposeful, active, and effective implementation work is done by implementation teams (NIRN, 2016). Active implementation incorporates best practices related to implementation stages that are established from an extensive review and synthesis of the implementation evaluation literature (Fixsen, 2005). During the exploration phase, readiness to implement the innovation is explored by implementation teams. Taking the time for exploration saves time and money (Fixsen, Blasé, Horner, Sims, \& Sugai, 2013) and improves the chances for success (Fixsen, 2005; Saldana, Chamberlain, Wang, \& Brown, 2011; Slavin, Cheung, Holmes, Madden, 2011).

To evaluate program readiness, implementation teams must consider program similarities, efficiency, cost, the fit with current initiatives, organizational structures, and how well there is a capacity to implement. Decisions about whether an innovation is a good fit within 
the context that it will be implemented (i.e., classroom, school division,) need to be made up front by involving all relevant stakeholders (i.e., instructors, principals) in the adoption, design, implementation, and evaluation so that they can express their ratings of satisfaction and acceptability (Luiselli, 2015; Van Dyke, 2016). All too often, implementation of innovations, initiatives, or programs are selected prematurely and must be adapted or replaced (Fixsen, 2005). Concurrently, active implementation relies on implementation team's use of improvement cycles to support the purposeful process of change. The plan-do-study-act (PDSA) cycle (Taylor et al., 2013) of implementation involves a trial and learning approach in which the PDSA steps are conducted over iterative cycles that are designed to discover and solve problems. This approach leads to achieving high standards while eliminating errors. PDSA cycles involve developing a plan, carrying out the test, observing and learning from the consequences, and determining what modifications should be made (Institute for Healthcare Improvement, 2017). Small focus groups can implement the innovation on a smaller scale as a pilot program so that the information can be utilized within the exploration stages of implementation as adoption decisions are explored.

\section{Summary}

ICs provide coaching to classroom instructors around evidence-based models, interventions, and strategies. The Competent Learner Model provides one example of a model that employs instructional coaching to support instructor and student growth. Within any model that uses coaching, time must be dedicated to training the staff members who provide coaching to teams. Instructional coaching best practices include modeling (i.e., skills, reflective conversations), direct observation, immediate performance-based feedback, and reflective 
dialogue for on-going professional development and should be used by ICs who provide training to professionals who are learning how to be ICs.

Traditional coaching occurs on-site with both the IC and CIT who is being coached. However, coaching has evolved to include online virtual platforms (i.e., Skype, Zoom conferencing). Virtual coaching is effective for school divisions to reduce travel time, and decrease costs. Live performance-based feedback provided by the IC to CITs cannot occur without additional tools such as "bug-in-ear" technology where coaching recipients receive feedback through a Bluetooth device. However, the IC can only observe what is occurring in the classroom (i.e., instruction, student engagement) within the width of the camera.

Too often in public schools, innovations are adopted without careful consideration of the usability within the existing system (i.e., school or classroom) and how the innovation aligns with other practices already in place. This study examined the use of live-stream smart glasses teleconferencing as a delivery method for instructional coaching. Research has demonstrated the effectiveness of the Competent Learner Model on instructor's skill and student's growth. This study utilized CLM as the model of choice as CITs coached classroom instructors while receiving coach training from the IC. The feasibility to utilize best practices in instructional coaching (i,e., observation, model, performance-based feedback, and reflective dialogue) when providing coach training was examined from the perspectives of the IC and CITs.

A small group of CITs tested the smart glasses teleconferencing system during the delivery of instructional coaching to CITs. Differences between on-site, face-to-face and virtual coaching via the smart glasses teleconference system were investigated. The CITs evaluated the experience of receiving coaching via the teleconference system. Suggestions from CITs for 
future implementation of instructional coaching using the smart glasses teleconference system is discussed.

\section{Research Questions}

This study addressed the following research questions.

1. What differences, if any, are there in efficiency, coaching strategies delivered by the IC to CITs, and cost during face-to-face coaching as compared to coaching received via the smart glasses teleconference system?

2. What is the difference (if any) in CITs perception of skill acquisition, knowledge gained, and satisfaction with face-to-face coaching verses coaching received via the smart glasses teleconference system?

3. How do CITs evaluate the experience of receiving coaching via the smart glasses teleconference system?

4. What are CITs suggestions for effective implementation of coaching via the smart glasses teleconference system? 


\section{Method}

\section{Participants and Setting}

The study included three participants purposefully sampled (Palinkas et al., 2015) from a regional CLM implementation in Virginia which included 50 implementation classrooms, 16 CITs, and eight certified coaches. The regional program supports the special education services of seven school divisions. One of the programs that the regional program uses is the Competent Learner Model. Special education directors work with the CLM Coordinator to select classrooms that will be identified as "CLM Classrooms."

Training is provided by the regional program to professionals in the division (i.e., Behavior Analysts, instructors, related service providers) that the special education director has identified to be ICs within the Competent Learner Model. CITs receive professional development around the multi-faceted components of the model as they provide coaching to classroom instructors (i.e., paraprofessionals, instructors) who provide instruction to students with disabilities or have difficulty participating in General Education settings.

This study occurred in two rural divisions that participate in collaboration with the regional program. Division One is a rural school division consisting of nine elementary schools, four middle schools, and five high schools. The identified professional to receive training in the Competent Learner Model was a Board Certified Behavior Analyst (BCBA) whose job included having an itinerant position providing behavior analytic support to five schools within the division, including one Competent Learner Model classroom implementation. Ronnie, the BCBA, had 14 years experience as an assistant residential coordinator at a private school for students with disabilities. He had previous exposure to CLM as an intern and six months of coaching experience as a CLM coach-in-training. He was assigned to a high school classroom 
that served students with intellectual disabilities. The classroom included a teacher, three instructional support staff, and ten students.

Morgan and Lorena* provided coaching in a rural division consisting of three elementary schools, three middle schools, and three high schools. Two professionals identified to receive coach training included a Behavior Analyst and a high school teacher.

Morgan (Behavior Analyst) provided support to all nine schools in the division including one CLM classroom implementation. Morgan had fours years of experience as a Behavior Analyst in two private schools for students with disabilities for three years, and one year in public schools. She had seven months coaching experience as a CLM CIT. Morgan was assigned to a pre-school classroom located within the high school building because of lack of space for the pre-school classroom at the elementary school. Students in the classroom walk to the elementary school to have access to their same age peers. The classroom consisted of a teacher and two support staff. Students included 20 students, five of whom were students with disabilities, as identified by their Individualized Education Plans.

Lorena was a teacher of a post-secondary vocational and life skills classroom for students with disabilities, ages 18-21. She had three years teaching experience at the elementary level, teaching students with autism. During this time, she implemented the Competent Learner Model; however, she was not identified as a CIT, so she received no additional coach training in the model. During the 2017-2018 school year, she was identified as a CLM CIT and provided coaching to the staff members in the post-graduate classroom. The classroom included two instructional assistants, one job-coach, and one volunteer. Additionally, the classroom had 12 students with disabilities who received vocational and life skills training in locations within the 
community. All CITs had no previous experiences with a smart glasses teleconference system.

\section{Researcher's role}

The investigator provided instructional coaching to CITs through traditional on-site coaching and virtual coaching with the smart glasses teleconference system. She has three years teaching experience as a special educator, four years' experience as a Behavior Analyst and IC for implementing the Competent Learner Model, and two years' experience as a Coordinator for a regional Competent Learner Model initiative. She also has seven years' experience providing instructional coaching to classroom teams including the use of on-site coaching, virtual coaching using Zoom video conferencing, and bug-in-ear coaching.

\section{Materials}

The smart glasses teleconference system was used for virtual coaching sessions. The teleconference features include high definition audio and video communication, the ability to send and receive calls directly to the eyewear, and secure communication with encryption options. Figure 1 shows how the point-of-view voice teleconference system is used for conferences. All calls occurred through a non-recording cloud-based server. The Pivothead company, the maker of the smart glasses teleconference system, had no access to any calls completed through the teleconference application.

Materials used by the CITs during virtual coaching sessions included smart glasses with a battery pack. Smart glasses were pre-programmed to the school's internet servers. The IC used the PivotSIP web-based application on a Mac Book Pro. The PivotSIP application was used by the IC to make and receive calls to the smart glasses worn by the CIT. Reflective conversations 
with CITs occurred through the use of Zoom video conference platform.

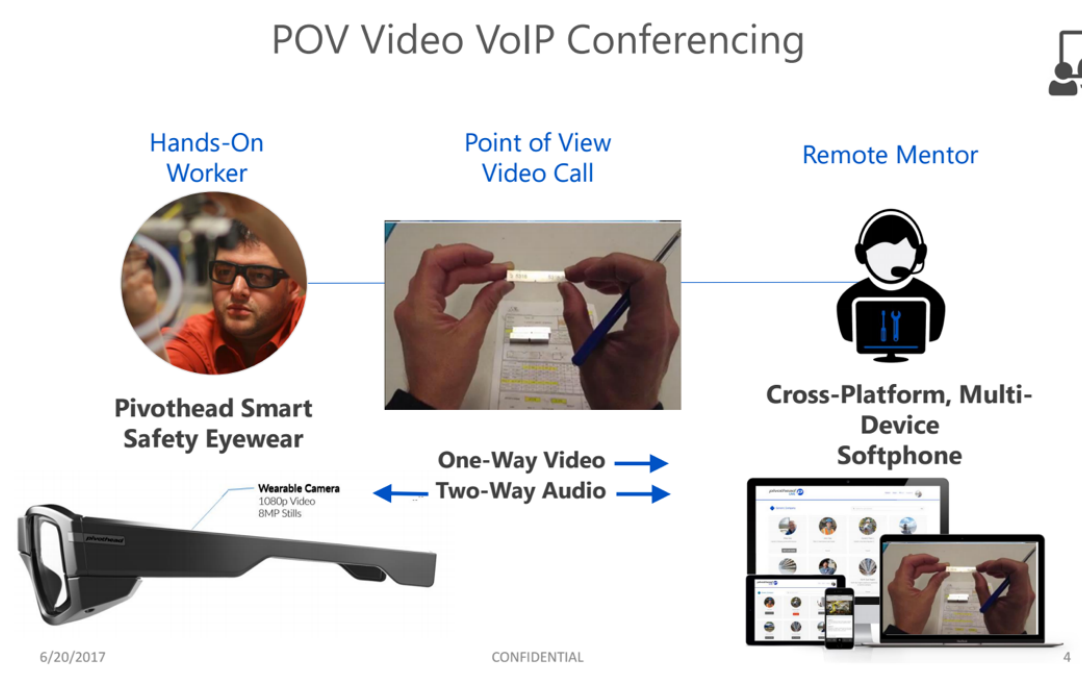

Figure 1. The point-of-view video conferencing. Pivothead telepresence pilot brief.

\section{Design}

The study is a multiple case study that involved direct observation of three CITs.

Interviews with all three CITs and field notes focused on the implementation of the coaching via the smart glasses teleconference system. Case study research is an effective research design to investigate contemporary phenomenon within its real-life context and is especially useful when the boundaries between phenomenon and context are not evident (Yin, 1989). Coaching received via the smart glasses teleconference system was compared to on-site, face-to-face training of CITs.

Purposeful sampling, member checking, non-biased observations, and multiple data sources were used to enhance the trustworthiness and credibility of the case study data. As part of the plan-do-study-act cycles, retrospective probing interviewing after each coaching session was utilized to gain feedback regarding the limitations, usability, coaching satisfaction, and perspectives of CITs regarding the knowledge and skills acquired (Ellis \& Levy, 2010). 


\section{Measures}

Field notes were crafted by the IC to document observations related to the coaching sessions. Suggestions for implementation of virtual coaching from the IC was also captured in the field notes. The investigator and CIT recorded all coaching practices used by the IC during coaching including observation, modeling, performance-based-feedback, and reflective dialogue. These instructional coaching practices were utilized with CITs as they applied coaching to instructors learning the components of the Competent Learner Model.

Three CITs completed a post-training interview after the completion of training on how to use the smart glasses teleconference system. Additionally, a post-coaching interview occurred after each coaching session. Finally, an end of experience interview was conducted after the completion of six coaching sessions per participant (see Appendix A). The training interview consisted of five open-ended questions, with specific probes added as needed related to the training on how to use the teleconference system. The post-conference coaching interview consisted of completing the coaching log, and five open-ended questions addressing CITs experiences with the type of coaching delivery model (i.e., virtual or face-to-face) received. The CIT end of experience interview protocol consisted of seven open-ended questions focusing on the CITs experience using smart glasses compared to on-site coaching. All interviews were recorded via Zoom video conferencing and kept in a password protected folder on the ICs computer.

\section{Procedures}

This study was approved by the West Virginia University Institutional Review Board for the Protection of Human Subjects in Research. Upon signed consent, CITs immediately began 
wearing the smart glasses anytime they were delivering coaching to assigned classrooms so that there was a desensitization period for all instructors and students in the classroom.

Randomization was used to schedule six two-hour coaching sessions (three on-site, and three virtual) for each CIT. Thus, the type of coaching was not set according to the classroom activities but was pre-set in a random order across all three CITs. CITs communicated the coaching schedule to all classroom team members in the CLM classroom they were assigned to as a CIT. The schedule was communicated to instructors who worked in the classroom so that they knew when to expect both the IC and CIT on-site, and when the CIT would be on-site independently but being coached through the smart glasses teleconference system by the IC. Concurrently, the investigator worked with the technology department in each school division and the technical support staff at Pivothead to set-up the equipment at each classroom site to ensure that the technology was working properly.

Smart glasses teleconference training. Training occurred in a private location. The training included information about how to use the smart glasses teleconference system. All CITs received a handbook with a task analysis for each essential function of the smart glasses teleconference system they might need, including procedures to follow if problems occurred, and how to properly care for the smart glasses. Participants practiced making and receiving calls. After training, all CIT were interviewed. The interview gathered their feedback about training components that were useful to them and any other feedback to inform future training (see Appendix A).

Treatment. Each CIT received at least two hours of mentor coaching weekly, either onsite or virtually, for six weeks. There were three weeks of virtual coaching and three weeks of on-site coaching to support the coaching delivered to instructors. Each coaching session provided 
by the IC to CITs was considered as a "plan-do-study-act" cycle to adjust the delivery of coaching method if needed.

Plan. While the type of instructional coaching received by CITs was determined at the beginning of this study, the agenda for the designated coaching week was identified a week before to the coaching implementation through the post-coaching interview process. The agenda included the IC and CIT who identified the goal for each coaching session.

Do. The IC provided coaching to the CITs using the strategies identified as best practices for coaching. These included modeling, inserting performance-based feedback, observation, and reflective dialogue, depending on the goal of the coaching session. CITs provided coaching to their classroom teams based on the core components of the Competent Learner Model teambased professional development program (For more information see: Competent Learner Model for Individuals with Autism/PDD, 2005). No coaching sessions were recorded.

During virtual coaching sessions, the IC was alone in a remote location. The CIT called the IC to initiate the coaching session. The IC answered the call using the PivotSip application, a live-stream cloud platform by the Pivothead Company. If someone entered the location where the IC was providing coaching, the call was discontinued and started again when the person exited. This process ensured confidentiality. If CITs needed to debrief through a reflective conversation, the CIT and IC met via Zoom video conferencing. However, all other coaching interactions occurred through the smart glasses teleconference system.

During on-site sessions, the IC was present with the CIT in the classroom in which they were assigned. Observation, modeling, and side-by-side coaching occurred within the classroom, but reflective conversations occurred in private locations outside of the classroom. 
Study. After the completion of each coaching session, the IC and CIT met for a brief (20 minutes) post-coaching interview, either on-site or via Zoom conferencing. Both the IC and the CIT completed the coaching $\log$ which required both the IC and CIT to indicate the specific types of strategies used by the IC during the activities provided by the CIT to the classroom instructors. The IC asked the CIT open-ended questions to gather information on how CITs perceived the instructional coaching they received. They were also asked for suggestions about how to improve the coaching they received. (see Appendix A).

Act. This information was then used to make improvements to subsequent coaching sessions.

Evaluation. At the end of the six-week period, each CIT met virtually with the IC to complete an end of experience interview via Zoom video conferencing. The interview focused on the CITs overall experience with both delivery methods (smart glasses teleconference system, and on-site).

\section{Results}

\section{Efficiency of instructional coaching to CITs}

Efficiency was investigated regarding cost, travel time, ease of use, and coaching strategies used by the IC to CITs that occurred during both types of coaching delivery models. Post-coaching and end-of-experience interviews were analyzed using content analysis with deductive category development about efficiency. Supplemental narrative comments provided by CITs revealed their perspectives on efficiency during both types of delivery models. Similarly, the ICs field notes were analyzed with deductive category development to determine the ICs perspective on the efficiency of each delivery model. 
On-site coaching required the IC to spend a total of 12 hours traveling. The smart glasses teleconference system did not require travel time. Anecdotal comments by CITs suggest that virtual coaching was, therefore, more time efficient. CITs stated, "If you don't have to drive so much, it will allow more time for coaching," and "We were able to reschedule easily, where before that just wasn't an option."

The following submissions were written on the ICs field notes during coaching sessions regarding efficiency.

You can hear amazing! I can hear both the teacher and the students. The high definition video is incredible. You can feel it! It is like you are there!

A huge advantage of this type of coaching is the ability to go with the CIT wherever they go. I could "walk down the hallway" to the gym with Morgan and the pre-school class and never lost signal.

Other ideas that were generated from the ICs field notes included the ability to observe the CITs exhibiting intrapersonal coaching behaviors without the intrusiveness of another person located in the classroom, the ability to directly observe the CIT (instead of hearing what occurred in the classroom through a reflective conversation), and the ease of inserting feedback.

Coaching best practices used by the IC. Coaching logs were reviewed and compiled into an Excel document to compare coaching practices used by the IC to the CIT. Instructional coaching strategies included observation, modeling, inserting performance-based feedback, and engaging in reflective dialogue. Post-coaching and post-experience interviews were analyzed using directed content analysis with deductive category development. Initial codes were developed from best practices of coaching (observation, model, performance-based feedback, and reflective dialogue) and core competencies within the Competent Learner Model. Main themes were reported using descriptive statistics with supplemental narratives. Figure 2 shows 
the instructional coaching practices used by the IC to CITs while they provided coaching to classroom instructors during on-site and virtual sessions.

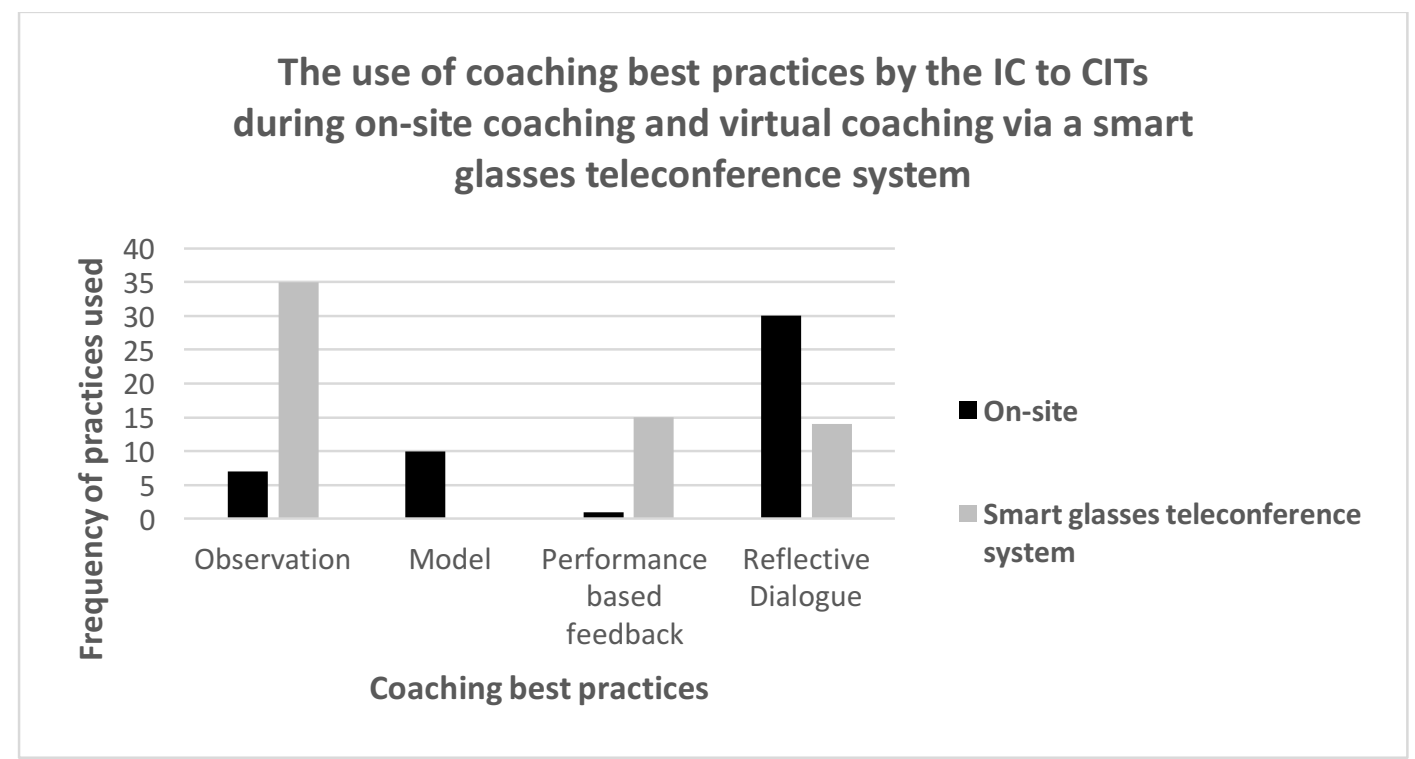

Figure 2. The use of coaching best practices used by the mentor coach to CITs

The IC could directly observe CITs more frequently during virtual coaching sessions compared to on-site coaching. One CIT noted that during the direct observation provided by the IC, that "The staff members came over to see what I was doing. They don't do that when we are both in the room," and "I don't have to describe what happened in the classroom, you just were able to observe it."

Additionally, the IC delivered performance-based feedback to CITs more frequently during virtual coaching than during on-site coaching. During a virtual coaching session, Morgan's goal was to become more familiar with the supplemental curriculum (i.e., embed student individualized instructional targets) in the Competent Learner Model. Morgan wanted to experience using the supplemental curriculum with an individual student so that she would be comfortable providing coaching. Morgan explained her experience obtaining performance-based feedback: 
You told me what to say, and there wasn't an interruption to the student or the instruction, and I felt like I could get true feedback. It is kind of like hand-over-hand prompting that cuts out the lag time.

During end-of experience interviews, all CITs stated that they preferred the use of the smart glasses teleconference system for receiving performance-based feedback. CITs felt that the smart glasses teleconference system was, however, difficult to use during activities where the IC would provide lengthy or complex explanations (i.e., facilitating conversations or team meetings) which they would then have to re-state the information to classroom instructors. However, CITs felt that the IC attending team meetings via Zoom video conferencing, was an efficient, alternative way to do this if the IC was not able to be on-site. Additionally, modeling by the IC occurred less during virtual coaching, as compared to on-site coaching.

Cost. The total cost for each on-site coaching session was determined by the following formula: (total miles traveled X .40 + duration of coaching X \$200.00). Virtual coaching cost was calculated by: $(\$ 800.00 / 9+\$ 200.00)$. Figures were generated from the school divisions’ mileage reimbursement, hourly pay distribution of the IC, cost of the teleconference system, and the total number of virtual coaching sessions. Per day totals were summed for each CIT, CITs costs were totaled, and total unit of analysis was reported. The average cost for on-site coaching for a two- hour period was $\$ 700.00$. Concurrently, the average cost for coaching delivered by the teleconference system was $\$ 400.00$ for each two-hour coaching session. Thus, virtual coaching may be less expensive than on-site, face-to-face coaching.

\section{CITs skill acquisition, knowledge gained, and satisfaction}

Post-coaching and end of the experience interviews were transcribed by the investigator. Content analysis with inductive category development was used. Data analysis began by reading the data repeatedly to obtain a sense of the whole (Hsieh \& Shannon, 2011; Tesch, 1990). Then, 
interviews were read word by word to derive codes by first highlighting exact words that captured key concepts of skill acquisition, knowledge gained, and coach satisfaction (Miles \& Hubermnan 1994; Morgan, 1993; Morse \& Field, 1995). Next, the researcher made notes about impressions and thoughts. Initial labels for codes were then developed. Codes were then sorted into categories based on how the codes were related (Hsieh, 2011). Main themes were reported in a descriptive narrative based on the central theme of the CITs overall satisfaction with instructional coaching received, skill acquisition, and knowledge gained during both virtual and on-site coaching.

CITs expressed that on-site coaching increased their understanding of intrapersonal coaching behaviors and professional knowledge related to the core competencies of the Competent Learner Model. Ronnie: It is helpful when you reviewed the content in the professional development modules with me so that I can make sure I knew what to cover with instructors. Reviewing these modules help me feel more confident in applying coaching around these concepts.

Megan: The discussions are very personalized to what I need. It was helpful to discuss strategies to develop relationships with instructors and principals.

Similarly, Lorena described the IC's use of positive reinforcement during on-site coaching. This helped her feel confident in using planned ignoring (a behavioral concept learned in the CLM model) with a student who was engaging in undesirable behaviors.

Having your assurance during the transition of student B from morning meeting, was helpful in the team feeling confident we were applying the right strategy.

All CITs commented on the ability of the IC to provide immediate feedback. This was helpful to increase their understanding of concepts related to the core components of the Competent

Learner Model.

Morgan: CLM has very specific Discriminative Stimuli (SD's) so it was helpful for you to be able to tell me what to say so that I become more familiar in implementing the supplemental curriculum with individual students. 
Lorena: I really liked the immediate feedback you provided to use an error correction procedure (behavioral concept used in the CLM) you gave me when student A was not responding. I totally had missed it, and then was like oh yeah!

Ronnie: It was cool because when instructor A asked me a question about the use of choral responding (a concept within CLM to build fluency and student engagement) you could provide an answer to me immediately so that we (instructor and CIT) didn't have to wait a week until you were on-site or forget the question we had. This was helpful in helping me to understand how to help instructor A apply choral responding with two students.

The CITs also shared examples of their satisfaction with both types of coaching delivery

models. Ronnie and Morgan expressed satisfaction with the use of reflective conversations with the IC when on-site coaching occurred.

Morgan: When you are on-site, I feel like I get more out of the use of reflective conversations when we can talk about the things we need to touch base about. For coaching in the classroom, I like the immediate feedback through the smart glasses

Ronnie: When we talk about how all the parts of the Competent Learner Model are connected that is helpful for me to understand the full picture.

I was holding a lot in until you came on-site because I knew I really needed to talk and that you would help get me through it.

Morgan and Lorena discussed when the IC modeled facilitation skills with the classroom instructors was related to satisfaction of on-site coaching.

Morgan: I like when you jump in during the team meetings because I'm like, I don't know what to say.

Lorena. I felt better about having you present because it was a hard subject to discuss with the team (debriefing about a student who had been in crisis) that involved a lot of emotions. It was good for us to see how you modeled how to have difficult conversations.

Similarly, Morgan described the immediacy of feedback related to satisfaction with virtual coaching. Ronnie and Lorena observed that the ability of the IC to directly observe was satisfying.

Morgan: I really liked it, it completely took away the reactivity piece. I mean I am going to keep saying this over and over again, but I like it provides it immediate feedback 
Ronnie: I appreciated having you observe today via the smart glasses because the classroom dynamics were different with the teacher being out. It was cool for me for you to be able to see what I had been seeing in the paraprofessionals ability to run the classroom. The type of coaching allowed us to gain something that we don't normally get to access.

Lorena: I really like the smart glasses, it makes me less nervous. I like how you can still see the coaching I am providing and provide coaching to me, but it doesn't change the classroom dynamics.

\section{CITs evaluation of the smart glasses teleconference system}

To explore how CITs evaluated the experience of receiving coaching via the smart glasses teleconference system post-training, coaching, and end-of experience interviews were converted into verbatim transcriptions. Content analysis with deductive category development was utilized. Initial codes were developed using Davis’ (2009) Instrument for Screening Programs and Practices for Adoption. This instrument includes a set of criteria that potential adopters should examine when considering a new practice (i.e., technology, program, curriculum). Coding began with predetermined codes (Hsieh, 2011) consisting of effectiveness, relative advantage, minimum standards for replication, complexity, compatibility, and costs. These directly relate to the factors that were examined during the exploration phases of implementation. The investigator made impressions of the initial codes. From these impressions, subcodes were developed under each main category, grouped according to similarities, and compared to on-site coaching where applicable. Main themes were reported in a descriptive narrative based on the central themes that were identified. These themes are ease of use, immediate feedback, point-of-view observation, satisfaction, utility, and limitations.

Ease of use. Approximately three sessions occurred before ease of technology was noted, mostly due to the IC being new to the set-up and working within the technology constraints of each school division. All CITs reported that the smart glasses teleconference system was "easy to 
use." CITs added: "It just kind of went off without a hitch," and "I couldn't believe how easy they were to use!"

All CITs described the coaching provided by the IC using the smart glasses teleconference system as less intrusive and more natural than on-site coaching. For instance, CITs stated: "It wasn't a distraction for anyone," "It was better because there wasn't someone right there watching me," and "It naturally takes away from the reactivity component. Ronnie added about the transition between side-by-side coaching and reflective conversations: "The transition didn’t feel as intrusive or secretive."

Immediate feedback. Another theme that was consistent across CITs was the ability for the IC to provide immediate feedback in the moment. CITs observed that the immediate feedback given by the IC was a helpful coaching practice to improve their delivery of the behavioral or instructional programming during virtual coaching. Direct observation totals identified on the coach log identified 15 total core components in the Competent Learner Model where the IC provided feedback compared to only two times during on-site coaching.

Point-of- view observation. CITs identified the ability for the IC to observe what they saw as an advantage as compared to on-site coaching. Within nine coaching sessions, the IC observed CITs engaging in 31 activities, as compared to the eight direct observations during onsite coaching. A CIT described the observation of a staff member implementing functional communication training with a student: "I felt that the smart glasses teleconference system allowed us to get something we don't normally get to access." Lorena added, "You can see what I see- I think it just makes things easier."

Satisfaction. All CITs described the experience of using smart glasses as positive and gave examples of successes they had within the three virtual coaching sessions. A central theme 
around individual and classroom success was apparent. Ronnie shared, "We were able to experience some great moments kids and staff that we just couldn't have experienced if you were on-site," and "We were able to observe little things together that we weren't able to observe together before." Similarly, Morgan added, "We got student A following single-step directions and doing more with you in my eyes and ears."

Utility in applied settings. CITs saw the value in this type of innovative coaching model for the Competent Learner Model. CITs also described other applications including, (1) with students with disabilities in community settings, (2) professions that employ an instructional coaching model, (3) evaluations by administrators to ease reactivity and lessen the anxiety of instructors, and (4) remote observation of students by various professionals. Lorena commented: "I can't think of a place in my daily routine that I couldn't use them."

Limitations of technology. CITs observed that the smart glasses teleconference technology could be a limitation for the delivery of instructional coaching. However, technology issues were minor. All CITs alluded to challenges with technology that might occur during initial set-up and training, i.e., "Technology was a limitation because you had a tough time getting them going, but once we got the kinks ironed out, it was no problem.” Additionally, Lorena was unable to use the smart glasses teleconference system during one instructional coaching session because she was needed to assist a staff member in the community setting with a student engaging in undesirable behaviors. However, she noted, "I guess this could be a limitation of any coaching method." And lastly, Morgan expressed wearing the smart glasses was sometimes a distraction to students in the pre-school learning environment.

He was really excited about the glasses, so he liked to follow me around....He was the only one that picked up that someone was on the other end. 


\section{Suggestions for implementation}

To address the final research question, CITs suggestions for effective implementation of the smart glasses teleconference system was explored by analyzing all interviews and field notes using content analysis with inductive category development. Data analysis began by reading the data repeatedly to obtain a sense of the whole (Hsieh, $2011 \&$ Tesch, 1990). Codes derived from highlighted words that were related to suggestions for implementation (Miles, 1994; Morgan, 1993; Morse, 1995), and notes recorded regarding the researcher's thoughts. Initial labels for codes were developed and sorted into categories to report main themes as identified by the CIT and IC. Key themes generated from the ICs field notes included set-up and the coaching infrastructure. Interviews transcribed from CITs generated additional themes of training and technical problems.

Set-up of the smart glasses teleconference system. Central themes identified from the

ICs field notes included the time dedicated to the set-up of the smart glasses teleconference system. Collaboration with the technology department and the Pivothead staff helped to make the training and coaching sessions more effective, from the perspective of the IC. The IC could troubleshoot solutions with the Pivothead support staff. This eased the frustration of the IC during the initial set up of the smart glasses. Each technology department in each school division had to set-up the teleconference system on their network, including whitelisting certain sites so that calls could be made. The technology department of one school division could not clear the appropriate filters. Thus, the smart glasses teleconference system could not be used because the school divisions filters were blocking the calls from the smart glasses. A hotspot was then purchased to overcome this problem. Ronnie carried the hot spot in his shirt pocket so that he could have wifi access to make teleconference calls using the smart glasses. 
Smart glasses teleconference system training. CITs reported that the following training components were helpful: (1) the combination of videos shown; (2) modeling how to use the smart glasses; (3) the smart glasses handbook; (4) a task analysis for making and receiving calls; and, (5) practice sessions. However, during all three trainings, problems occurred with the technology due to the lack of mastery and fluency with programming the smart glasses to the local wifi and programming the smart glasses to speed dial directly to the ICs computer.

While this did not seem to have an impact on the comfort of CITs using the teleconference system, limited time for training was noted. Lorena added, “If someone isn't as familiar or comfortable with technology, they might need more time to practice until they have mastered the content."

Training did not include practice sessions where students and instructors were in the classroom. CITs provided suggestions for additional training components on the use of the smart glasses teleconference system. Lorena suggested,

I think it would be good to have a dry run with actual students and instructors in the classroom where the IC inserts the feedback so that the CIT can get used to listening to your comments while other things are going on in the classroom. I think this would be helpful with instructors who do not have as much experience with technology and would help to lessen their anxiety when first using this system.

During training sessions with CITs, examples were shown regarding the use of the teleconference system. The use of the smart glasses teleconference system was explained to staff members and students, but not shown. Ronnie suggested:

I think it would be good to just add into the training, a component where the teleconference system is shown and explained to students and instructors as well. I think it would be good to explain to other professionals in the building about the teleconference system, especially if you are going to wear the smart glasses in the hallway.

Technical challenges. Several technical problems were discussed during post-coaching interviews that suggested adjustments could be made for subsequent teleconference coaching 
sessions. CITs feedback included, "I got a lot of kick, back from your computer- I think it might help if you use headphones," and "I could hear you typing." The IC noted other suggestions, including making use of the mute button, muting all electronic alerts before sessions begin, and having a copy of print materials that the CIT will be using or referencing.

Coaching infrastructure. A coaching infrastructure is important to the successful implementation and adoption of the smart glasses teleconference system. A coaching infrastructure refers to the program have established goals and participant roles, school leader participation, adequate time and resources, and a meaningful plan for program evaluation (Hanover Research, 2015). This study was completed within an already established coaching model around the core components of the Competent Learner Model. CITs and the IC understood the outcomes they were trying to achieve during each coaching session. For example, during all on-site coaching sessions with Lorena, the coaching objective included having Lorena (the CIT) observe the IC as she modeled reflective questioning, and maneuvered difficult conversations with instructors during team meetings. Similarly, during an on-site coaching session with Ronnie, the IC reviewed the content in one of the CLM professional development modules. The content focused on how to condition stimuli as reinforcers using the processes of pairing and correlating (concepts learned in CLM). During the next coaching session, the objective was for Ronnie to discuss the content learned in the module with instructors so that they could complete the process of pairing and correlating to have adequate reinforcing stimuli (changing the value of aversive stimuli, look for features of other stimuli that have similar features as reinforcing stimuli, and condition neutral stimuli as potential reinforcers) for each learner. The IC directly observed Ronnie's ability to tutor participants in the content learned in the online professional development module so that instructors could use the concepts of pairing 
and correlating to develop adequate stimuli to affect behavior change with their learners.

Additionally, the IC observed for Ronnie's ability to establish a collaborative relationship and maintain positive rapport with all staff members. Delayed feedback was given after Ronnie provided supplemental coaching to the team.

Field notes indicated that within the existing coaching infrastructure, the IC and CITs need time to debrief after the coaching session so that they can engage in reflective conversations. Next, the delivery of coaching can be changed, as needed.

During the plan, do, study, act cycles for each coaching session, technological components could be changed for the next coaching session if needed. An example of a plan, do, study, act cycle with a CIT is provided below.

Plan. IC: Let's plan for coaching next week. We had discussed that we would continue to keep the objective of completing the student assessments while providing coaching to the paraprofessionals. Is that still the plan?

CIT: Yes. My plan is to complete at least five categories, and then have the paraprofessionals complete the same five categories, so that we get two data points for each of these categories.

IC: Great. Sounds like a plan. I will observe your coaching and delivery of the assessment and give feedback as needed.

Do- A two-hour coaching session occurred. The IC did not interject many statements because the assessments were performed correctly by both the CIT and instructors.

Study-IC: Is there anything that you want to change for next time?

CIT: Yes actually- There were times that I wasn't sure if you were there or not, because it had been awhile since you said anything. Can you try to give me a little bit more feedback, even if is just that you are there?

Act: During the next coaching session, the IC set a timer and said a statement to the CIT at least every five minutes. During the next plan-do-study-act cycle, the CIT indicated that the frequency of feedback and statements was much better so that she knew that the call had not dropped. 
Other changes adjusted during the plan-do-study-act cycles were to use the mute button by the IC, and use of earbuds, which CITs described as being effective for limiting background noises.

\section{Discussion}

The purpose of this study was to examine the differences in cost, efficiency, and coaching strategies used by the IC when coaching CITs in the Competent Learner Model during face-toface and virtual coaching. Similarly, skill acquisition and knowledge gained, and satisfaction from the perspectives of CITs was examined Additionally, CITs evaluated their experience of receiving coaching delivered through the virtual smart glasses teleconferencing system. Finally, CITs and the IC provided suggestions for how to improve virtual delivery of coaching.

Findings suggested differences in perceived efficiency of instructional coaching. Virtual coaching was judged as a more efficient delivery mechanism than on-site coaching. The average amount of driving time saved during virtual coaching was 1.5 hours a day. Similarly, the average difference in cost between onsite and virtual coaching was $\$ 232$. However, this included $\$ 88$ per coaching session for the smart glasses teleconference system equipment. Every school division's costs and return on investment will be calculated differently, depending on the division size, miles traveled, costs of personnel for an instructional coach, and the number of smart glasses systems needed for virtual coaching.

Differences between on-site coaching and virtual coaching were observed regarding the strategies used by the IC when providing coaching the CITs. The IC directly observed 23 more coaching activities, inserted immediate performance-based feedback during 14 more activities, and engaged in nine less reflective conversations with CITs during virtual coaching as compared 
to on-site coaching. However, during virtual coaching sessions, modeling did not occur as compared to occurring during 10 activities during on-site coaching.

The two types of coaching delivery models addressed different skills and knowledge. Onsite coaching increased CITs understanding of intrapersonal coaching behaviors (i.e., using reflective questioning, developing trust, establishing collaborative relationships) and didactic coach professional knowledge (i.e., concepts in the professional development modules, the progression of a classroom CLM implementation). Virtual coaching received by the smart glasses teleconferencing system addressed the concrete skills (i.e., supplemental curriculum and instruction) in the Competent Learner Model. There were no differences in CITs satisfaction with coaching when coached on-site or virtually. CITs indicated satisfaction with both types of delivery of coaching methods.

The CITs indicated that they would prefer to receive coaching through a combination of on-site and virtual teleconferencing. Findings support the use of a blended coaching delivery model. Blended coaching using virtual and face-to-face delivery is potentially cost-effective for schools having limited resources (Emerling, Young, \& Tatsui, 2015).

CITs reported that virtual teleconferencing increased the ICs ability to provide performance-based feedback and to directly observe the CITs ability to provide coaching to instructors around the core components of CLM. Additionally, CITs reported that the coaching received virtually was less intrusive to the classroom learning environment, and an easier and more effective way to obtain immediate performance-based feedback from the IC. These findings are consistent with bug-in-ear coaching approaches where instructors report that virtual coaching with covert feedback is less intrusive than on-site coaching (Rock, 2014).

Because the use of smart glasses for virtual coaching is in the early stages of adoption, 
benefits for users and the performance functions of this technology should be emphasized (Rauschnabel \& Ro, 2017). The adoption of innovations requires school division support developed by facilitative administrators (i.e., superintendents, principals, non-teaching staff) to change practices and support system structures (i.e., technology) so that a hospitable environment exists for the use of effective innovations (NIRN, 2016). School divisions should be prepared to devote appropriate attention to support for instructional coaching personnel, as well as to the technical support that will be needed to implement virtual coaching. School divisions should consider consulting with an outside expert to set-up the technology and train the trainer or IC who will be responsible for providing support to the initiative (i.e., technology, curriculum) (Bertram, Blasé, Fixsen, 2014).

It is recommended that ICs collaborate with other professionals (i.e., technology staff) to work out technology issues. ICs should have mastery of the virtual technology system before beginning virtual coaching. Recipients of virtual coaching can be located anywhere that they have wifi access. When determining the sequence and pace of adoption of virtual coaching, school divisions should consider the technical challenges that may arise which will vary from settings (Porter, 2017).

The findings demonstrated that the training components for using the smart glasses teleconference system helped CITs feel comfortable when using the system and receiving virtual coaching. Training included a description of skills, modeling of new skills, and practice with feedback (Kealey, Peterson, Gauk, \& Dinh, 2000). These are essential to helping CITs feel comfortable when using new technology.

Stakeholder involvement through the exploration phases of implementation is a critical component of readiness and pre-adoption activities (Norris, White, Norwell, Mrklas, \& Stelfox, 
2017). This study only considered the perceptions of CITs and the IC. Including all stakeholders (i.e., principals, instructors) is important for the successful adoption and implementation of innovations in public schools.

A dominant design and use of smart glasses teleconferencing systems for virtual coaching have not occurred in public school settings. Complex systems of public school require intentional, systematic processes so that haphazard, costly adoption of innovations are avoided. Best practices for adoption of innovations during exploration phases of implementation (Davis, 2009) should be followed. The IC and CITs in this study observed that the virtual conferencing method was cost- and time- efficient. Also, the IC could observe CITs and provide immediate feedback, and do so unobtrusively. Finally, the virtual coaching technology (smart glasses) was easy to use. As a result, all CITs preferred combining on-site and virtual teleconferencing for instructional coaching.

\section{Implications for Practice}

The findings from this study have implications for school divisions that are considering adopting virtual smart glasses teleconferencing systems to deliver coaching to instructors or CITs. Smart glasses teleconference systems have not been used by educators for either coaching or professional development. Public school leaders should consider the fit, need, resource availability, cost, and capacity to implement the virtual coaching (Blasé, Kiser, Van Dyke, 2013) including those that use smart glasses. Virtual teleconferencing systems may increase efficiencies, decrease costs, and support the delivery of instructional coaching. Smart glasses teleconferencing systems may also be less intrusive than on-site coaching, allow for ICs point-ofview observation, enable performance feedback during coaching sessions, are easy to use, and can be used in a variety of ways in schools and classrooms. 
The findings describe CITs suggestions for virtual coaching in schools. Future adopters should consider these suggestions during the exploration phase of implementation, before adoption. New technology should be aligned with school divisions mission, vision, and classroom teaching models. School leaders should also understand how the technology fits with current technology plans, the purposes virtual coaching aims to serve, and how the adoption of virtual teleconferencing for instructional coaching impacts student achievement.

The CITs in this study enjoyed using the smart glasses teleconferencing system to receive performance-based feedback and the direct observation by the IC. However, CITs also preferred a combination of on-site coaching and virtual coaching over one delivery method or the other. Similarly, the usability of the smart glasses teleconference system to directly observe and provide performance-based feedback to CITs has implications for the delivery of coaching to instructors and CITs using the Competent Learner Model. Regional Associates of the Competent Learner Model, should consider the use of virtual coaching with international partners to decrease travel time, and costs. This may also increase the global expansion of the model because of the ability to provide remote coaching without having to be on-site.

\section{Implications for Research}

Investigations of the effectiveness of smart glasses teleconferencing systems for instructional coaching for improving specific teaching skills are needed. While the findings suggest satisfaction with virtual smart glasses teleconferencing systems for instructional coaching, by CITs, studies are needed to evaluate the social validity of CITs beliefs that virtual smart glasses teleconferencing makes a valuable contribution to instructors and student outcomes (Wolf, 1978). Finally, virtual smart glasses teleconferencing systems should be compared to other types of e-coaching methods, including bug-in-ear coaching. 


\section{Limitations}

This study is one of the first descriptions of the adoption and use of a virtual smart glasses teleconference system. An exploratory case study was used, to understand the feasibility of virtual technology for delivering instructional coaching to CITs. A limitation in the use of an exploratory case study includes the inability to identify causational relations. Additionally, this study uses a small sample size of participants from two rural school divisions in Virginia. Thus, the results are not generalizable to other instructional coaching programs considering the adoption of the smart glasses teleconference system. All three CITs had experience with face-toface coaching with the investigator, who served as the IC. Although strategies recommended by Creswell (2013) were implemented to ensure the credibility of the qualitative data, participants may have felt they needed to speak in favor in the use of the virtual smart glasses teleconferencing system for coaching because of the existing instructional coaching relationship. This study was limited to three CITs perspectives of their experiences, satisfaction, skill acquisition, and knowledge gained from receiving instructional coaching delivered through the smart glasses teleconferencing system. Therefore, the actual effectiveness of instructional coaching on instructors' or students' behaviors was not examined.

\section{Conclusion}

The findings described differences between on-site and virtual coaching (smart glasses teleconferencing system) from the perspectives of CITs. The responses of three CITs who received coaching were described. CITs and the IC provided suggestions for improving effective implementation of virtual teleconferencing. CITs preferred a combination of onsite and virtual coaching using the smart glasses teleconferencing system. The technology is user-friendly, cost- 
effective, and can increase ICs observations and ability to provide performance-based feedback.

Schools should allow adequate time for adequate training and system set-up. 


\section{References}

Aguilar, E. (2014). Effective coaching by design. Educational Leadership, 71(8). 70-73

Aguilar, Elena. (2016). The Art of Coaching Teams: Building Resilient Communities that Transform Schools. San Francisco, CA. Jossey-Bass.

Augmented Reality for Enterprise Network (2016). Smart glasses adoption in the enterprise

[White paper]. Retrieved January 9, 2018, from Vital Enterprises:

https://www.vital.enterprises/assets/downloads/VitalEnterprises-

SmartGlassWhitepaper.pdf

Ahrend, G., Diamond, F.; Webber, G. (2010) 'Virtual coaching: using technology to boost performance, Chief Learning Officer, July, pp.44- 47.

Blase, K., Kiser, L., Van Dyke, M. (2013). The hexagon tool: Exploring content. Chapel Hill: National Implementation Research Network.

Beatram, R., Blasé, K., Fixsen, D. (2014). Improving programs and outcomes. Research on Social Work and Practice, 25(4), 477-487.

Brestlow, N (2017). Technology takes coaching to scale- Investing in innovation grantees show how it's done. The Learning Professional, 38(6), 54-62.

Brock, M. E., Cannella-Malone, H. I., Seaman, R. L., Andzik, N. R., Schaefer, J. M., Page, E. J., ... Dueker, S. A. (2017). Findings across practitioner training studies in special education: A comprehensive review and meta-analysis. Exceptional Children, doi:10.1177/0014402917698008https

Chamberlain, K. (2008). Case study: Professional development that enhances teaching and learning (Doctoral dissertation). Available from ProQuest Dissertations and Theses database. (UMI No. 3371525) 
Creswell, J. W. (2013). Research Design: Qualitative, Quantitative and Mixed Methods Approaches (4th ed.). Thousand Oaks, CA: Sage.

Coogle, C. G., Rahn, N. L., \& Ottley, J. R. (2014). The impact of bug in ear feedback at a distance on pre-service teachers' use of environmental arrangement communication strategies. Manuscript submitted for publication.

Darling-Hammond, L. (2000). Futures of teaching in American education. Journal of Educational Change, 1, 353-373. doi:10.1023/A:1010034806982

Dakelab, W., Hedge, C., \& Sundstrom, L. (2017). Active implementation at the national cooperative highway research program: Frameworks for moving research into practice. Transportation Research News. 310, 29-36.

Davis, J. S. (2009). An instrument for screening new practices for adoption (Tech.). doi:http://nirn.fpg.unc.edu/sites/nirn.fpg.unc.edu/files/resources/DavisPracticeScreeningInstrument-11-2009.pdf

Duda \& Barrett (2014). Systems coaching: Coaching for competence and impact. Brief \#1 Ehsanipour, T. \& Zaccarelli, F.G. (2017). Exploring coaching for technology use. Retrieved from http://digitalpromise.org/wp-content/uploads/2017/07/Dynamic-Learning-ProjectPaper-Final.pdf

Ellis, T. \& Levy, Y. (2010). A guide for novice researchers: Design and development research methods. Proceedings of Informing Science \& IT Education Conference.

Emerling, B., Tatsui, T., \& Young, K. (2015). Virtual coaching for instructional leaders: A multi-method investigation of technology-enabled external assistance. Teachers College Record, 117(11). 
Fixsen, D., Naoom, F., Blase, K., Friedman, M., \& Wallace, F. (2005). Implementation research: A synthesis of the literature. The National Implementation Research Network. 231.

Fixsen, D., Blasé, K., Horner, R., Sims, B., \& Sugai, G. (2013). Scaling-up brief. State implementation of evidence based practices. Retrieved from http://sisep.fpg.unc.edu/sites/sisep.fpg.unc.edu/files/resources/SISEP-Brief3ReadinessForChange.pdf?o=aihub

Fullan, M. (2009). Large-scale reform comes of age. Journal of Educational Change, 10, 101113. doi:10.1007/s10833-009-9108-z

Greenhalgh, T., Robert, G., Macfarlane, F., Bate, P., \& Kyriakidou, O. (2004). Diffusion of innovations in service organizations: Systematic review and recommendations. The Milbank Quarterly, 82(4), 581-629. http://doi.org/10.1111/j.0887-378X.2004.00325.x

Hall, L. J., Grundon, G. S., Pope, C., \& Romero, B. (2010). Training paraprofessionals to use behavioral strategies when educating learners with autism spectrum disorders across environments. Behavioral Interventions, 25, 37-51.

Hanover Research. (2014). Trends in higher education, marketing, recruitment, and technology. Retrieved from https://www.hanoverresearch.com/media/Trends-in-Higher-EducationMarketing-Recruitment-and-Technology-2.pdf

Hineline, P., \& Axelrod, S. (2009). Evaluating intensive behavioral interventions for autism. Organization for Autism Research. Temple University.

Hsieh, H., \& Shannon, S. (2005). Three approaches to content analysis. Qualitative Health Research. 15(9), 1277-1288. doi: 10.1177/1049732305276687. 
Ippolito, J. (2010). Three ways that literacy coaches balance responsive and directive relationships with teachers. Elementary School Journal, 111(1), 164-190.

Institute of Healthcare improvement. Improving health and health care worldwide. Retrieved from http://www.ihi.org/resources/Pages/Tools/PlanDoStudyActWorksheet.aspx

Kealey, K. A., Peterson, A. V., Jr., Gaul, M. A., \& Dinh, K. T. (2000). Teacher training as a behavior change process: Principles and results from a longitudinal study. Health Education \& Behavior, 27(1), 64-81.

Ketley, C. (2017). Knowledge of applied behavior analysis principles as an outcome of instructional coaching (Unpublished doctoral dissertation). West Virginia University, Morgantown.

Kissinger, M. H. (2014). Competent learner model: A study of teacher self-efficacy and satisfaction with coaching for special education teachers and instructors (Unpublished doctoral dissertation). The College of William and Mary, Williamsburg, Virginia.

Knight, J. (2009). Coaching: Approaches and perspectives. Thousand Oakes, CA: Corwin Press.

Kretlow, A. G., \& Bartholomew, C. C. (2010). Using coaching to improve the fidelity of evidence-based practices: A review of studies. Teacher Education and Special Education: The Journal of the Teacher Education Division of the Council for Exceptional Children, 33(4), 279-299. doi:10.1177/0888406410371643

Kubina, R., \& Wolfe, R. (2007). Evaluation of the competent learner model project in Pennsylvania (2006-07): Executive summary (Unpublished research summary to PaTTAN), The Pennsylvania State University.

Kucharczyk, S., Shaw. E., Smith Myles, B., Sullivan, L., Szidon, K., \& Tuchman-Ginsberg, L. (2012). Guidance \& coaching on evidence-based practices for learners with autism 
spectrum disorders. Chapel Hill: The University of North Carolina, Frank Porter Graham Child Development Institute, National Professional Development Center on Autism Spectrum Disorders.

Luiselli, J. K. (2015). Staff preparation and performance management: Applied. Autism Service Delivery Autism and Child Psychopathology Series, 465-489. doi:10.1007/978-1-49392656-5_17

Mendicino, M. (2015). The effects of partnership-based collaborative consultation on treatment integrity, skill acquisition, and reducing problematic behaviors. (Unpublished doctoral dissertation). West Virginia University, Morgantown.

Miles, M. B, \& Huberman, A. M. (1994). Qualitative data analysis: An expanded sourcebook. Thousand Oaks, CA: Sage.

Morgan, D. L. (1993). Qualitative content analysis: A guide to paths not taken. Qualitative Health Research, 3, 112-121

Morse, J.M., \& Field, P.A. (1995). Qualitative research methods for health professionals $2^{\text {nd }}$ ed. Thousand Oaks, CA: Sage.

Mraz, M., Algozzine, B., \& Watson, P. (2008). Perceptions and expectations of roles and responsibilities of literacy coaching. Literacy Research and Instruction, 47(3), 141-157.

National Implementation Research Network. (2016). Implementation brief: Active implementation practice and science. University of North Carolina, Chapel Hill.

Neufeld, B., \& Roper, D. (2003). Coaching: A strategy for developing instructional capacityPromises and practicalities. Washington, DC: Aspen Institute. 
Neuman, S., \& Cunningham, L. (2009). The impact of proessional development and coaching on early language and literacy instructional practices. American Educational Research Journal 46(2), 532-566.

Norris, J., White, D., Norwell, L., Mrklas, \& Stelfox, H. (2017). How do stakeholders from multiple hierarchical levels of large provincial health system define engagement? A qualitative study. Implementation Science 12(98)

Palinkas, L., Horwitz, M., Green, A., Wisdom, J., Duan, N., \& Hoagwood, K. (2015). Purposeful sampling for qualitative data collection and analysis in mixed method implementation research. Administration and Policy in Mental Health, 42(5), 533-544. http://doi.org/10.1007/s10488-013-0528-y

Pierce, J. D. (2015). Teacher-coach alliance as a critical component of coaching: Effects of feedback and analysis on teacher practice (Doctoral dissertation, University of Washington). Retrieved from http://hdl.handle.net/1773/33786

Pivothead telepresence pilot brief [PDF]. (2017). Denver: Pivothead.

Polly, A. (2013). The relationship between teacher satisfaction with coaching and teacher efficacy in autistic support classrooms (Unpublished doctoral dissertation). Nova Southeastern University, Fort Lauderdale, Florida.

Porter, M., \& Happelmann, J. (2017). A conceptual model of adaptation to retirement among athletes: A meta-analysis. Harvard Business Review

Quintis, L. (2011). A phenomenological examination of barriers to implementing best teaching practices learned during coaching (Doctoral dissertation). Available from ProQuest Dissertations and Theses database. (UMI No. 3461463) 
Rauschnabel, P., Brem, A., \& Ivens, B. S. (2015). Who will buy smart glasses?: Empirical results of two pre-market-entry studies on the role of personality in individual awareness and intended adaption of Google Glass Wearables. Computers in Human Behavior.

Rock, M. L., Schumacker, R. E., Gregg, M., Howard, P. W., Gable, R. A., \& Zigmond, N. (2014). How are they now? Longer term effects of eCoaching through online bug-in-ear technology. Teacher Education and Special Education, 37, 161-181. doi:

$10.1177 / 0888406414525048$

Rock, M. L., Gregg, M., Howard, P. W., Ploessl, D. M., Maughn, S., Gable, R. A., \& Zigmond, N. (2009). See me, hear me, coach me. Journal of Staff Development, 30(3), 24-26.

Rossides, D. (2004). Knee-jerk formalism: Reforming American education. Journal of Higher Education, 75, 667-703. doi:10.1353/jhe.2004.0039

Saldana, L., Wang, W., \& Brown, C. H. (2012). Predicting program start-up using the stages of implementation measure. Administration and Policy in Mental Health and Mental Health Services Research, 39, 419-425.

Scheeler, M. C., Ruhl, K. L., \& McAfee, J. K. (2004). Providing performance feedback to teachers: A review. Teacher Education and Special Education, 27(4), 396-407.

Scott, T. M., \& Martinek, G. (2006). Coaching positive behavior support in school settings: Tactics and data-based decision making. Journal of Positive Behavior Interventions, 8(3), 165-173.

Scutta, C. (2017). Competent learner model Education White Paper. Tucci Learning Solutions Shanklin, N. L. (2006). What are the characteristics of effective literacy coaching? Urbana, IL: Literacy Coaching Clearinghouse. Retrieved from http://www.literacycoachingonline.org/briefs/charofliteracycoachingnls09-27-07.pdf 
Shidler, Linda. (2008). The impact of time spent coaching for teacher efficacy on student achievement. Early Childhood Education Journal. 36. 453-460. 10.1007/s10643-0080298-4.

Slavin, R., Cheung, A., Holmes, G., Madden, N., \& Chamberlain (2011). The effects of a datadriven district reform model on state assessments. Institute for Education Science, U.S. Department of Education. Retrieved from http://www.successforall.org/wpcontent/uploads/2016/02/Effects-of-a-Data-Driven-District-Reform-Model-July-2011.pdf

Snyder, P. A., Hemmeter, M. L., \& Fox, L. (2015). Supporting implementation of evidencebased practices through practice-based coaching. Topics in Early Childhood Special Education, 35(3), 133-143.

Solomon, B. G., Klein, S. A., \& Politylo, B. C. (2012). The effect of performance feedback on teachers' treatment integrity: A meta-analysis of the single-case literature. School Psychology Review, 41(2), 160-175

Sparrow, S., Cicchetti, D., \& Sauliner, C. (2016). Vineland Adaptive Behavior Scales-Third Edition [Measurement instrument]. Retrieved from https://www.pearsonclinical.com/psychology/products/100001622/vineland-adaptivebehavior-scales-third-edition--vineland-3.html

Stormont, M., \& Reinke, W. (2012). Using coaching to support classroom-level adoption and use of. interventions within school-wide positive behavioral interventions and systems. University of Missouri. US Department of Education.

Taylor, M., McNicholas, C., Nicolay, C, Darzi A., Bell, D., \& Reed, J. (2013). Systematic review of the application of the plan-do-study-act method to improve quality in healthcare. BMJ Quality \& Safety, 23(4), 290-298. 
Tesch, R. (1990). Qualitative research: Analysis types and software tools. Bristol, PA: Falmer. Terry, K. (2010). Compliance, commitment, and capacity: Examining districts' responses to No Child Left Behind. Planning and Changing, 41, 80-109.

Tucci, V. (2005). Effective learning environments. Encyclopedia of Behavior Modification and Cognitive Behavior Therapy (pp. 1286-1290). Thousand Oaks: SAGE Publication

Tucci, V., \& Hursh, D. (1988). Developing competent learners by arranging effective environments. Behavior Analysis in Education from the Journal of Applied Behavior Analysis, Reprint Series, Volume 3 (Behavior Analysis in Education) (pp. 257-264). St. Louis: Journal of Applied Behavior Analysis.

Tucci, V., \& Hursh, D. (1991). Competent learner model: Instructional programming for teachers and learners. Education and Treatment of Children, 14(4), 349-381.

Tucci, V., Hursh, D., \& Laitinen, R. (2004). The competent learner model: A merging of applied behavior analysis, direct instruction, and precision teaching. Evidence-Based Educational Methods, 109-123.

Tucci, V., Hursh, D., Laitinen, R., \& Lambe, A. (2005). Competent learner model for individuals with autism/PDD. Exceptionality, 13(1), 55-63.

Van Dyke, M. (2016). Active implementation frameworks integrate the science and practice of implementation. [PDF document]. Retrieved from https:/gic.globalimplementation.org/app/uploads/2016/10/gic-2015-program.pdf Varlas, L. (2010). Education funding: Underwater and overdue for reform. Info brief, 16, 1-6. Retrieved from 
http://www.ascd.org/publications/newsletters/policypriorities/vol16/issue3/full/Education -Funding@-Underwater-and-Overdue-for-Reform.aspx

Warash, B., Curtis, R., Hursh, D., \& Tucci, V. (2008). Skinner meets piaget on the reggio playground. Journal of Research in Childhood Education, 22(4), 441-453.

Wehby, J. H., Maggin, D. M., Partin, T. C. M., \& Robertson, R. (2012). The impact of working alliance, social validity, and teacher burnout on implementation fidelity of the good behavior game. School Mental Health, 4(1), 22-33.

White, A. S., Howell Smith, M., Kunz, G. M., \& Nugent, G. C. (2015). Active ingredients of instructional coaching: Developing a conceptual framework (R2Ed Working Paper No. 2015-3).

Winton, P., Snyder, P., \& Goffin, S. (2015). Rethinking professional development for early childhood teachers. In L. Couse \& S. Recchia (Eds.), Handbook of Early Childhood Teacher Education (pp. 54-68). New York: Routledge.

Wolf, M. M. (1978). Social validity: the case for subjective measurement or how applied behavior analysis is finding its heart. Journal of Applied Behavior Analysis, 11(2), 203214. http://doi.org/10.1901/jaba.1978.11-203

Yin, R. K. (1989). Case Study Research Design and Methods. New Deihi, Londan. Sage Publications. 
Appendix A

\section{INTERVIEW PROTOCOLS}

\section{Post-Training Interview Protocol}

1. Tell me about the training on virtual coaching via smart glasses?

2. Tell me about the components of the training were helpful in learning how to use the smart glasses system.

3. Tell me about the components of the training that were not helpful in learning how to use the smart glasses system.

4. Describe aspects of the training that could be improved.

5. Any specific suggestions or recommendations should this training occur again?

- Content, instructional delivery, handouts, behavioral skills training, role play, videos

\section{Post Coaching Conference Interview Protocol}

1. Based off of the Coach in Training for replicability form, today we completed (list all activities that the mentor coach provided coaching around.) Can you describe how you are feeling about the coaching the classroom team received today?

- How do you think the coaching was received?

2. Please describe how you are feeling about the type of mentor coaching you received today?

- Challenges, coach delivery, technological issues

3. Any suggestions for the next coaching session to make the mentor coaching more effective?

- Feedback delivery, coaching strategies, technology improvements

4. Based on the coaching session today and where the staff members are currently, let's make an agenda for next week's coaching session. (Coach and mentor coach will then make an agenda for next week's coaching session).

5. Any other comments, suggestions, or thoughts regarding the coaching session you would like to discuss?

\section{CIT End of Experience Interview Protocol}

1. Please explain your overall experiences with the coaching methods you received.

- Likes, dislikes, satisfaction,

2. Describe how coaching via smart glasses compares to traditional face-to-face coaching (if any)?

- Similarities or differences, performance feedback, support, ability to receive coaching around CLM concepts

3. Describe any coaching strategies used by the mentor coach that leant itself better to one type of coaching method over the other? 
- "Model, Lead, Test" contingency, performance-based feedback, checkouts, application of curriculum, team meetings

4. Please describe the challenges, successes, and/or limitations you experienced while receiving coaching via smart glasses?

- Technology issues, ability to receive coaching around CLM concepts, communication challenges, material set up, coaches proximity, performance-based feedback delivered in the moment, wearable technology, ability to connect with staff members

5. In your experience, describe the effectiveness of mentor coaching provided by smart glasses on your knowledge gained and/or your ability to apply concepts within the Competent Learner Model compared to on-site coaching.

- Ability to apply concepts, knowledge obtained, feedback obtained

6. Consider the following opportunity. Your company offers you a choice in the type of coaching method you will receive for mentor coaching within the Competent Learner Model. You can customize this package to your adult learning style and your preferences. You can choose one coaching method or a combination of methods. Describe the coaching method or methods you would choose.

7. Any other suggestions or ideas for future implementations of this type of coaching method? 